\title{
New Developments in Mechanical Ventilation
}

\author{
Daniel R Ouellette
}

Pulmonary and Critical Care Medicine, Henry Ford Hospital, Detroit, US

ositive pressure ventilation was developed in the 1950s as a way to treat respiratory failure due to ventilatory insufficiency. While lifesaving, mechanical ventilation, especially when prolonged, can be associated with a host of complications. Current advances focus on strategies to liberate patients from the ventilator. New guidelines have been published to aid practitioners in this area.

\section{Keywords}

Mechanical ventilation, Critical

Illness, Respiratory Failure

Disclosure: Daniel R Ouellette has nothing to disclose in relation to this article. This article is a short opinion piece and has not been submitted to external peer reviewers.

Authorship: All named authors meet the International Committee of Medical Journal Editors (ICMJE) criteria for authorship of this manuscript, take responsibility for the integrity of the work as a whole, and have given final approval to the version to be published.

Open Access: This article is published under the Creative Commons Attribution Noncommercial License, which permits any noncommercial use, distribution, adaptation, and reproduction provided the original author(s) and source are given appropriate credit.

Received: March 2, 2017

Published Online: April 19, 2017

Citation: US Respiratory \& Pulmonary Diseases, 2017;2(1):21-2

Corresponding Author: Daniel R Ouellette, Department of Pulmonary and Critical Care Medicine, Henry Ford Hospital, Detroit MI 48202, US. E: douelle1@hfhs.org

Support: No funding was received for the publication of this article.
Dr. Bjorn Ibsen suggested to medical leaders in Copenhagen, during the 1952 polio epidemic, that positive pressure ventilation might have beneficial effects in patients with polio afflicted with respiratory failure primarily related to deficiencies in alveolar ventilation. ${ }^{1}$ The success of positive pressure mechanical ventilation in saving lives in the early 1950s led to widespread use of this intervention, and helped to spur the development of the nascent field of critical care medicine.

Today, we understand that mechanical ventilation, as a therapy, represents a double-edged sword: on the one hand, it is a life-saving treatment, but on the other, it is associated with a host of complications. Critical care practitioners know that the duration of mechanical ventilation is directly associated with the incidence of adverse effects. ${ }^{2}$ Liberation of patients from mechanical ventilation at the earliest possible moment after they have begun to recover from their initial illness has become the focus of attention in the modern era.

The application of the principles of evidence-based medicine to the problem of liberation from mechanical ventilation, led to the publication of guidelines at the beginning of this century that outlined clinical strategies for critical care physicians. ${ }^{3}$ Macintyre and colleagues promoted several recommendations that physicians have adopted into daily practice. ${ }^{3}$ Chief among these are the use of spontaneous breathing trials (SBTs) as an assessment tool for readiness to be liberated from the ventilator, and the use of discontinuation protocols. Today, these techniques are part of the daily routine in the management of ventilated patients in intensive care units.

The American College of Chest Physicians (CHEST) and the American Thoracic Society (ATS) have recently collaborated to develop new evidence-based recommendations that inform practitioners about the process of ventilator discontinuation. ${ }^{4}$ The use of non-invasive ventilation following extubation in patients at high risk for re-intubation is a strong recommendation. ${ }^{5}$ Patients at high risk may include those with chronic obstructive pulmonary disease, those with congestive heart failure, and patients with a chronic respiratory acidosis. The guidelines also inform practitioners about the methods for performing SBTs, recommending that inspiratory pressure augmentation be employed during such trials. ${ }^{5}$ Physicians and their colleagues are advised to use protocols to minimize sedation, to institute protocols for rehabilitation to promote early mobilization, and to manage acutely hospitalized patients ventilated for more than 24 hours with ventilator liberation protocols. 5,6 Cuff leak tests are recommended for patients at high risk for post-extubation stridor; patients failing a cuff leak test should be treated with systemic steroids for at least 4 hours before extubation. ${ }^{6}$ Recommendations were developed by an expert panel that performed literature searches, meta analyses, and approved recommendations through a process of iterative Delphi voting.

Many advances have been made over the last 50 years in the application of mechanical ventilation to the care of patients with respiratory failure. The work of many scientists, researchers, guideline experts, with the support of societies like CHEST and the ATS, will ensure that practitioners can provide innovative and state-of-the-art life-saving treatments to critically ill patients in the future. 


\section{Editorial Mechanical Ventilation}

1. Berthelsen $P G$, Manual positive pressure ventilation and the Cophenhagen poliomyelitis epidemic 1952, Acta Anesthesiol Scand, 2014;58:503-7.

2. Boles JM, Bion J, Connors $\mathrm{A}$, C, et al., Weaning from mechanical ventilation, Eur Resp J, 2007:29:1033-56.

3. Macintyre NR, Cook DJ, Ely EW Jr, et al., Evidence-based guidelines for weaning and discontinuing ventilator support, Chest, 2001:120:375S-395S
4. Schmidt GA, Girard TD, Kress JP, et al., Liberation from mechanical ventilation in critically ill adults: Executive summary of an official American College of Chest Physicians/American Thoracic Society clinical practice guideline, Chest, 2017;151:160-5.

5. Ouellette DR, Patel S, Girard TD, et al., Liberation from mechanical ventilation in critically ill adults: An official American College of

ventilation in critically ill adults: An official American College of guideline: Inspiratory pressure augmentation during spontaneous breathing trials, protocols minimizing sedation, and noninvasive ventilation immediately after extubation, Chest, 2017;151:166-80 6. Girard TD, Alhazzani W, Kress JP, et al., An official American Thoracic Society/American College of Chest Physicians clinical practice guideline: liberation from mechanical ventilation in critically ill adults: rehabilitation protocols, ventilator liberation protocols, and cuff leak tests, Am J Respir Crit Care Med, 2017:195:120-33. 